\title{
The biogeochemical iron cycle and astrobiology
}

\author{
Christian Schröder ${ }^{1}$ • Inga Köhler ${ }^{2,5}$. \\ Francois L. L. Muller ${ }^{3}$. Aleksandr I. Chumakov ${ }^{4}$. \\ Ilya Kupenko ${ }^{4} \cdot$ Rudolf Rüffer $^{4}$ - Andreas Kappler ${ }^{2}$
}

Published online: 21 March 2016

(C) The Author(s) 2016. This article is published with open access at Springerlink.com

\begin{abstract}
Biogeochemistry investigates chemical cycles which influence or are influenced by biological activity. Astrobiology studies the origin, evolution and distribution of life in the universe. The biogeochemical Fe cycle has controlled major nutrient cycles such as the $\mathrm{C}$ cycle throughout geological time. Iron sulfide minerals may have provided energy and surfaces for the first pioneer organisms on Earth. Banded iron formations document the evolution of oxygenic photosynthesis. To assess the potential habitability of planets other than Earth one looks for water, an energy source and a C source. On Mars, for example, Fe minerals have provided evidence for the past presence of liquid water on its surface and would provide a viable energy source. Here we present Mössbauer spectroscopy investigations of $\mathrm{Fe}$ and $\mathrm{C}$ cycle interactions in both ancient and modern environments. Experiments to simulate the diagenesis of banded iron formations indicate that the formation of ferrous minerals depends on the amount of biomass buried with ferric precursors rather than on the atmospheric composition at the time of deposition. Mössbauer spectra further reveal the mutual stabilisation of Fe-organic matter complexes against mineral transformation and decay of
\end{abstract}

This article is part of the Topical Collection on Proceedings of the International Conference on the Applications of the Mössbauer Effect (ICAME 2015), Hamburg, Germany, 13-18 September 2015

Christian Schröder

christian.schroeder@stir.ac.uk

1 Biological and Environmental Sciences, School of Natural Sciences, University of Stirling, Stirling FK9 4LA, Scotland, UK

2 Geomicrobiology, Centre for Applied Geoscience, Eberhard Karls University of Tübingen, Sigwartstr. 10, 72076 Tübingen, Germany

3 Department of Biological and Environmental Sciences, Qatar University, PO Box 2713, Doha, Qatar

4 ESRF-The European Synchrotron, CS40220, 38043 Grenoble Cedex 9, France

5 Institute of Geosciences, Friedrich Schiller University of Jena, Burgweg 11, 07743 Jena, Germany 
organic matter into $\mathrm{CO}_{2}$. This corresponds to observations of a 'rusty carbon sink' in modern sediments. The stabilisation of Fe-organic matter complexes may also aid transport of particulate $\mathrm{Fe}$ in the water column while having an adverse effect on the bioavailability of Fe. In the modern oxic ocean, Fe is insoluble and particulate Fe represents an important source. Collecting that particulate Fe yields small sample sizes that would pose a challenge for conventional Mössbauer experiments. We demonstrate that the unique properties of the beam used in synchrotron-based Mössbauer applications can be utilized for studying such samples effectively. Reactive Fe species often occur in amorphous or nanoparticulate form in the environment and are therefore difficult to study with standard mineralogical tools. Sequential extraction techniques are commonly used as proxies. We provide an example where Mössbauer spectroscopy can replace sequential extraction techniques where mineralogical information is sought. Where mineral separation is needed, for example in the investigation of Fe or S isotope fractionation, Mössbauer spectroscopy can help to optimize sequential extraction procedures. This can be employed in a large number of investigations of soils and sediments, potentially even for mineral separation to study Fe and $\mathrm{S}$ isotope fractionation in samples returned from Mars, which might reveal signatures of biological activity. When looking for the possibility of life outside Earth, Jupiter's icy moon Europa is one of the most exciting places. It may be just in reach for a Mössbauer spectrometer deployed by a future lander to study the red streak mineral deposits on its surface to look for clues about the composition of the ocean hidden under the moon's icy surface.

Keywords Mössbauer spectroscopy · Iron bioavailability · Sequential extraction · Synchrotron Mössbauer Source (SMS)

\section{Introduction}

Biogeochemistry investigates chemical cycles which influence or are influenced by biological activity. Astrobiology studies the origin, evolution and distribution of life in the universe [1]. The element Fe plays a major role in both of these overlapping fields, which motivates a variety of Mössbauer spectroscopy investigations [2-5].

Iron sulphides such as mackinawite $(\mathrm{FeS})$, greigite $\left(\mathrm{Fe}_{3} \mathrm{~S}_{4}\right)$ and pyrite $\left(\mathrm{FeS}_{2}\right)$ play an important role in biogeochemical processes in anoxic soils and sediments [6]. These minerals have been around since the Hadean eon [7], and the iron-sulphur world hypothesis [8] posits iron sulphide mineral surfaces as energy source and template for the first pioneer organisms at the origin of life.

Banded Iron Formations (BIFs) are the world's oldest sedimentary deposits and provide insight into biogeochemical processes on early Earth $[9,10]$. They preserve signs of the evolution of oxygenic photosynthesis, while documenting the decline of probably widespread iron-based metabolisms before the great oxidation event.

The biogeochemical Fe cycle interacts with other major nutrient element cycles, in particular the $\mathrm{C}$ cycle, in a significant way. In today's oceans, for example, Fe is a limiting nutrient for growth and thus uptake of atmospheric $\mathrm{CO}_{2}$ by phytoplankton. Looking for the potential habitability of other planets, the most important prerequisites are water, an energy source, and a $\mathrm{C}$ source. The global deposition of Fe carbonates during the Noachian eon on Mars [11] provides evidence for the presence of liquid water on early Mars while also linking the $\mathrm{Fe}$ and $\mathrm{C}$ cycles on the Red Planet.

Here we present Mössbauer spectroscopy investigations of $\mathrm{Fe}$ and $\mathrm{C}$ cycle interactions in both ancient and modern environments. We show how Mössbauer spectroscopy can aid 



Fig. 1 The image on the left shows a gold capsule after it had been filled with a ferrihydrite-glucose mixture under anoxic conditions in a glovebox and welded shut. These gold capsules were then incubated at a temperature of $170{ }^{\circ} \mathrm{C}$ and a pressure of $1.2 \mathrm{kbar}$ for 1-100 days. The image on the right shows a capsule after incubation that was embedded in resin, cut in half, and polished for microscopy investigations

sequential extraction techniques and subsequent $\mathrm{Fe}$ and $\mathrm{S}$ isotope analyses. Looking into the future, we discuss how such investigations can be applied for example on samples that will be returned from Mars or in situ on a future landed mission to Jupiter's icy moon Europa.

\section{Experimental diagenesis of banded iron formations}

Banded Iron Formations (BIFs) were laid down in the Precambrian and represent the world's oldest sedimentary rock formations. They document the evolution of oxygenic photosynthesis and the rise of oxygen in the atmosphere and ocean. However, deciphering this record is hampered by diagenetic overprinting since their formation. Microorganisms are thought to have played a key role in BIF formation and were likely buried alongside Fe minerals. We experimentally simulated BIF diagenesis [12] to investigate the effect of biomass on mineral deposition and transformation. For this purpose, we incubated mixtures of ferrihydrite, $\mathrm{Fe}(\mathrm{OH})_{3}$ - as a proxy for biogenic ferric oxyhydroxide minerals, and glucose, $\mathrm{C}_{6} \mathrm{H}_{12} \mathrm{O}_{6}$ - as a proxy for microbial biomass, in gold capsules (Fig. 1) at $170{ }^{\circ} \mathrm{C}$ temperature and $1.2 \mathrm{kbar}$ pressure for 1-100 days. To determine the effect of different amounts of biomass, we investigated two different electron ratios of 0.6 and 2.4. The electron ratio is defined as electrons potentially released from carbon in glucose to the electrons potentially accepted by $\mathrm{Fe}$ (III) in ferrihydrite. Carbon in glucose is of neutral charge and can release four electrons during oxidation to $\mathrm{CO}_{2} ; \mathrm{Fe}$ (III) can accept one electron upon reduction to $\mathrm{Fe}(\mathrm{II})$. More details on the experimental procedure are provided by Posth and co-workers [12] and Köhler and co-workers [13].

We used Mössbauer spectroscopy to identify the minerals formed during the experimental procedure and to determine the $\mathrm{Fe}^{2+} / \mathrm{Fe}_{\text {total }}$ ratio. In some cases we extracted the material from the gold capsules and measured it as a powder in transmission (transmission spectra with absorption minima in Fig. 2). In other cases we obtained backscatter spectra (spectra showing emission maxima in Fig. 2) from capsules that had been embedded in resin, cut in half, and polished for microscopy investigations (Fig. 1), using the miniaturized Mössbauer spectrometer MIMOS II [14]. All spectra were obtained at room temperature using a ${ }^{57} \mathrm{Co}$ source in Rhodium matrix at constant acceleration.

Figure 2 shows a sequence of Mössbauer spectra taken after 7, 10, 14, and 100 days for each electron ratio. In the experiments with an electron ratio of 0.6 , ferrihydrite seems to initially mature into hematite, $\mathrm{Fe}_{2}^{\mathrm{III}} \mathrm{O}_{3}$, before the $\mathrm{Fe}(\mathrm{III})$ is gradually reduced by the $\mathrm{C}$ in glucose to form magnetite, $\mathrm{Fe}^{\mathrm{II}} \mathrm{Fe}_{2}^{\mathrm{III}} \mathrm{O}_{4}$, and siderite, $\mathrm{Fe}^{\mathrm{II}} \mathrm{CO}_{3}$. The amount of electrons 

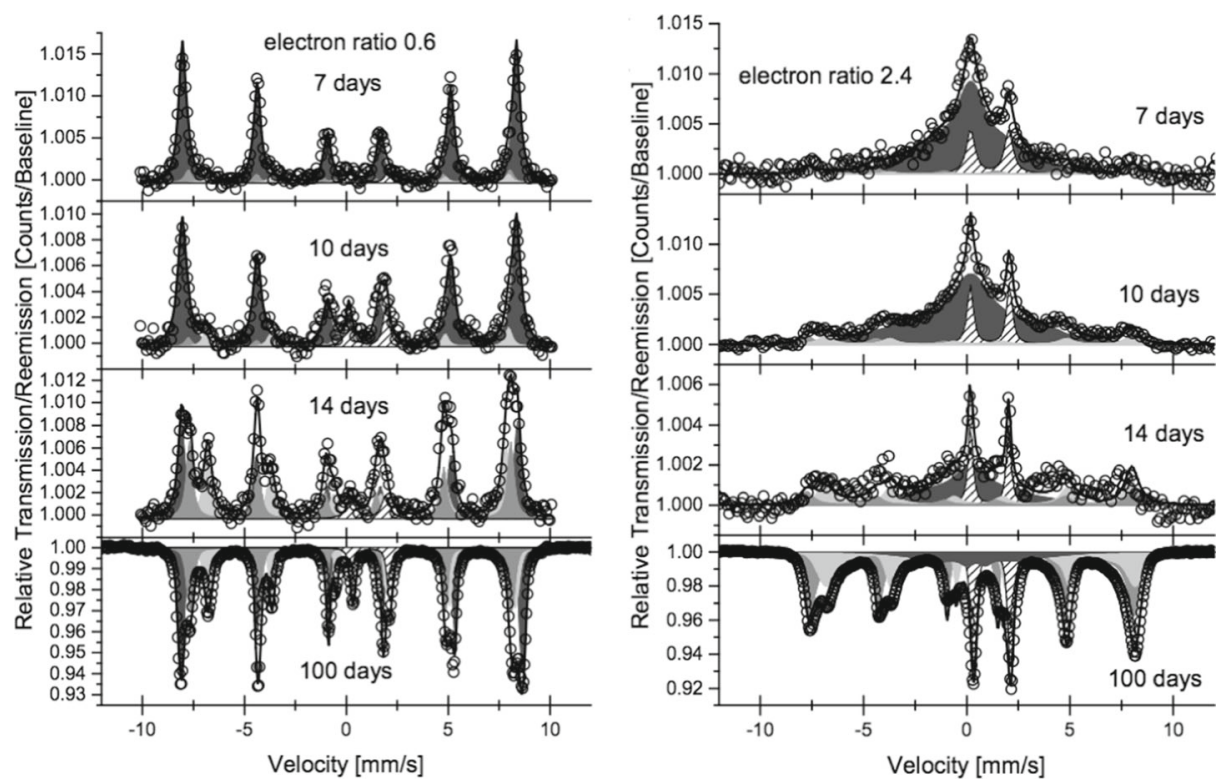

Fig. 2 Mössbauer spectra of ferrihydrite-glucose mixtures at electron ratio of 0.6 (left) and 2.4 (right) after incubation at $1.2 \mathrm{kbar}$ and $170{ }^{\circ} \mathrm{C}$ for runtimes of 7-100 days. Dark grey-hematite (0.6) or ferrihydrite (2.4); grey-magnetite $\mathrm{Fe}^{3+}$; light grey - magnetite $\mathrm{Fe}^{2.5+}$; hatched - siderite

available is not sufficient to reduce all of the hematite. In the experiments with an electron ratio of 2.4, $\mathrm{Fe}$ (III) is gradually reduced to form siderite and magnetite. Although there are enough electrons available, not all of the $\mathrm{Fe}(\mathrm{III})$ is reduced but the $\mathrm{Fe}^{2+} / \mathrm{Fe}_{\text {total }}$ ratio is significantly increased compared to the 0.6 electron ratio experiments. The most remarkable observation, however, is that ferrihydrite, rather than being transformed into a crystalline Fe-(oxyhydr)oxide such as hematite upon heat and pressure treatment, remains an amorphous or low-crystalline phase represented by the very broad and smeared-out sextet feature in Fig. 2.

The minerals formed in these BIF diagenesis experiments - hematite, magnetite, and siderite - are commonly found in BIFs. Their relative abundance as well as the $\mathrm{Fe}^{2+} / \mathrm{Fe}_{\text {total }}$ ratio in the experiments is a result of the initial mixing ratio of ferrihydrite to glucose. Therefore, relative Fe mineral abundance and Fe redox states in BIFs might represent the amount of biomass buried within the original sediment [12] rather than indicating atmospheric concentrations of methane and $\mathrm{CO}_{2}$ at the time of deposition [15].

The above results both find support from observations in and have implications for modern environments. Lalonde and co-workers [16] have shown that around $20 \%$ of organic carbon in marine sediments is directly bound to reactive Fe mineral phases. These stabilise the organic carbon against decay into eventually $\mathrm{CO}_{2}$ and therefore act like a 'rusty carbon sink'. It is thus conceivable that a significant amount of biomass was buried in Precambrian sediments and lasted until BIF diagenesis set in. Our results also demonstrate that this stabilising effect is mutual. The organic carbon in the 2.4 electron ratio experiments prevented fast mineral transformation of the generally transient ferrihydrite, even at elevated temperature and pressure.

This stabilising effect takes effect also in biologically mediated reactions, though whether bioreduction of Fe(III) minerals in sediments is decreased or enhanced appears to 
depend on the $\mathrm{C} / \mathrm{Fe}$ ratio. Shimizu and co-workers [17] investigated bioreduction rates of ferrihydrite co-precipitated with varying amounts of humic acids as a proxy for organic matter. At low $\mathrm{C} / \mathrm{Fe}$ ratios $\leq 0.8, \mathrm{Fe}(\mathrm{III})$ reduction by the dissimilatory iron-reducing bacteria Shewanella putrefaciens strain CN32 decreased compared to pure ferrihydrite. Reduction rates were enhanced at high $\mathrm{C} / \mathrm{Fe}$ ratios $\geq 1.8$. For comparison, the electron ratios of 0.6 and 2.4 in the BIF diagenesis simulation experiments described above translate into $\mathrm{C} / \mathrm{Fe}$ ratios of 0.15 and 0.6 , respectively. Note, however, that glucose and humic acids might interact in different ways with Fe minerals.

The processes described above are relevant in generally anoxic sediments or soils. In the oxic environment of the open ocean Fe is insoluble and often a limiting nutrient for phytoplankton growth. Particulate Fe is an important source of Fe in the ocean (see Section 4 below). While Fe-organic matter complexes may enhance transport of particulate $\mathrm{Fe}$, it may at the same time decrease its bioavailability.

\section{Sequential extraction and isotope analyses}

Reactive Fe species occur often as amorphous materials, colloids or nanoparticles, and are consequently difficult to identify using standard mineralogical tools such as X-Ray Diffraction (XRD). Sequential chemical extraction procedures [18-22] are therefore widely used as proxies. Sequential extraction procedures are without alternatives where minerals need to be separated, for example to characterise their isotopic signatures, but the mixtures are so intricate that physical methods such as micro-drilling or laser ablation no longer suffice. Poulton and Canfield [22] have developed a particularly powerful sequential extraction technique that divides highly reactive iron into carbonate iron, iron (oxyhydr)oxides, magnetite, pyrite, and silicate pools. The procedure has been applied to separate minerals for the study of e.g. iron or sulphur isotope fractionations between minerals and led to a series of high-impact papers determining euxinic or oxic conditions in the biogeochemical evolution of the Early Ocean and to trace the rise of atmospheric oxygen [23-25]. However, sequential chemical extraction relies on the distinct solubilities of minerals. Solubility is also governed by particle size and the degree of crystallinity or complexation with organic matter. Mineral grain sizes and degrees of crystallinity vary between sediments, leading to incomplete or premature dissolution of some mineral phases. Incomplete extraction of carbonate is a known problem [26,27]. Such interferences carry over to subsequent extractions and thus compromise the estimation of reactive iron. The efficiency of carbonate extraction as well as the iron speciation methodology should be validated independently in each case.

One goal of the BIF diagenesis simulation experiments described in the previous section remains to analyse the iron isotope composition of the product minerals. In a proof of concept project [28], Poulton and Canfield's [22] sequential extraction procedure was tested for its effectiveness in separating the individual iron minerals (Table 1, Fig. 3). The mineral products after high $\mathrm{P} / \mathrm{T}$ incubation and before any extraction steps were determined with XRD, reflected light microscopy and Mössbauer spectroscopy. All techniques confirmed the formation of hematite, magnetite, and siderite. In microscopy images, significant amounts of material showed no identifiable reflections. This material was initially labelled as unprocessed ferrihydrite. Ferrihydrite would not be identified by XRD against a backdrop of well-crystalline minerals. The hydroxylamine- $\mathrm{HCl}$ extraction step (Table 1, Fig. 3) produced some iron, which seemed to confirm the presence of ferrihydrite. Mössbauer spectroscopy, however, showed unequivocally that no ferrihydrite was present (Fig. 4). A Mössbauer spectrum obtained at cold temperatures showed instead two populations of 
Table 1 Extraction steps for BIF diagenesis experiments adapted from Poulton and Canfield [22] by Schmid [28]

\begin{tabular}{llll}
\hline & Extraction Stage & Target Phase & Terminology \\
\hline (1) & $1 \mathrm{M}$ sodium acetate & Siderite & $\mathrm{Fe}_{\text {carb }}$ \\
& $48 \mathrm{~h}, 50^{\circ} \mathrm{C}, \mathrm{pH} \sim 4.5$ & & $\mathrm{Fe}_{\text {ox } 1}$ \\
& $1 \mathrm{M}$ hydroxylamine- $\mathrm{HCl}$ & Ferrihydrite & \\
& $48 \mathrm{~h}, \mathrm{RT}$ & $\mathrm{Fe}_{\text {ox } 2}$ \\
& $50 \mathrm{~g} / \mathrm{L}$ sodium dithionite & Hematite & $\mathrm{Fe}_{\text {mag }}$ \\
& $2 \mathrm{~h}, \mathrm{RT}, \mathrm{pH} \sim 4.8$ & Magnetite & \\
& $0.2 \mathrm{M}$ ammonium oxalate & & \\
\hline
\end{tabular}

hematite. The larger fraction of the hematite was a poorly-crystalline form, in which the Morin transition was suppressed, and explains the unidentified material in the microscopy images. Another Mössbauer spectrum was obtained from a residual sample at room temperature after two extraction steps (Fig. 4). After these steps, siderite and any ferrihydrite should have been removed completely, while hematite and magnetite should still be present at their initial amounts. However, the Mössbauer spectrum shows that some siderite remains and much of the magnetite has been removed and/or oxidised. As a result, the extraction procedure was adjusted: Since there was no ferrihydrite, the second extraction step was removed from the protocol, and a better result for siderite extraction had been obtained with $0.5 \mathrm{M} \mathrm{HCl}$ for 15 hours, which should only remove low-crystalline iron minerals [20,21]. A Mössbauer spectrum obtained after this extraction step (not shown) reveals intact hematite and magnetite amounts, albeit minute amounts of siderite still remain.

These results demonstrate that Mössbauer spectroscopy can replace sequential extraction techniques where mineralogical information is sought. Where mineral separation is needed, for example in the investigation of Fe or S isotope fractionation, Mössbauer spectroscopy can inform upon incomplete or overreaching extractions and thus help to optimize sequential extraction procedures.

\section{Synchrotron-based Mössbauer spectroscopy of nanoparticulate iron delivered to the ocean}

The low availability of iron in large areas of the world's oceans limits photosynthesis by pelagic phytoplankton, which in turn influences atmospheric $\mathrm{CO}_{2}$ levels and hence global climate [29-31]. Bioavailability of iron in the ocean is constrained by speciation (dissolved iron), particle size (i.e. nanoparticles and colloids), association with C (see Section 2 above), and mineralogy. However, the mineralogical characterisation remains challenging as reactive iron often occurs in amorphous, colloidal or nanoparticulate form (see Section 3 above). Reviewing the iron biogeochemical cycle past and present, Raiswell and Canfield [32] urge: "It is now more important than ever that a more mineralogical view is adopted in future studies of the iron biogeochemical cycle in order to characterise colloids and nanoparticles, and define their role in aquatic environments."

The various pools of iron input into the ocean are a matter of ongoing research and their individual contributions are not yet well understood. There is growing recognition within 


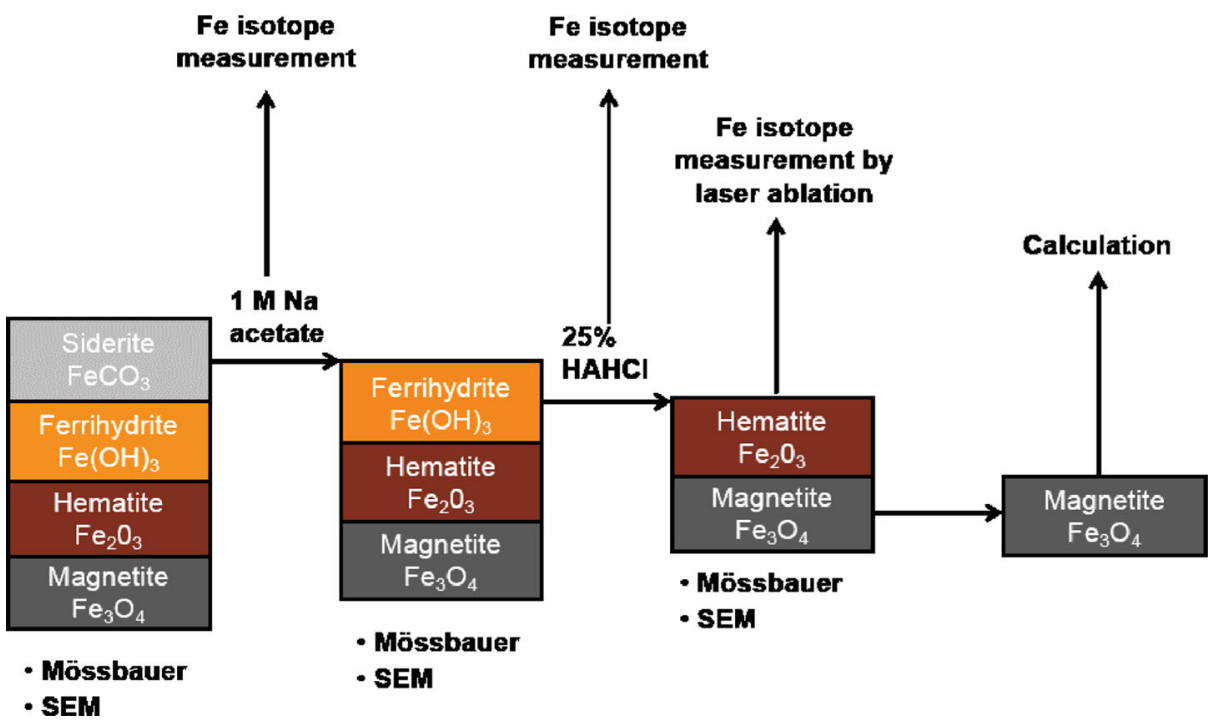

Fig. 3 Schematic drawing of the sequential extraction steps initially planned to investigate Fe isotope fractionation between minerals that formed in the BIF diagenesis simulation experiments (adapted from [28]). Mössbauer spectroscopy data (Fig. 4) revealed that mineral separation is not that straightforward

marine biogeochemistry that the importance of atmospheric iron inputs to the global ocean has been consistently overestimated until now, whereas that of rivers and/or groundwater inputs has been grossly underestimated. This situation arose because the global riverine iron input is based on the "average world river". In turn, these calculations use average compositions and total water discharge to the ocean by major world rivers, most of which exhibit extensive iron removal by flocculation and sedimentation during seawater mixing. Humic-rich, high latitude rivers, which recent work has shown to have a much higher ironcarrying capacity [33-35], are underrepresented in these calculations. Therefore it is very likely that a much greater amount of dissolved iron can escape estuarine removal and be transported to the open ocean than previously thought.

In Scotland, the short distance between many peatland drainage catchments and the coastal ocean facilitates source-to-sea research investigating transport, fate and mineralogy of iron-bearing colloids. In a preliminary study for an ongoing project, we have collected samples from the Halladale and Thurso rivers and a coastal seawater sample for comparison (Fig. 5). The Halladale and Thurso rivers are draining the Flow Country, the largest expanse of blanket bog in Europe. We performed vacuum filtration on a 100-um nylon mesh prefilter followed by a quartz fibre filter (nominal $0.7-\mu \mathrm{m}$ pore size), similar to methods described by Marcus and Lam [36]. We used the ${ }^{57} \mathrm{Fe}$ Synchrotron Mössbauer Source (SMS) [37] at the European Synchrotron Radiation Facility (ESRF) to analyse these samples.

The time to obtain a good quality Mössbauer spectrum is directly proportional to the amount of $\mathrm{Fe}$ in a sample. Particulate Fe in water is dilute and even concentration by filtering will not enable the collection of the optimal amount of $\mathrm{Fe}, \sim 10 \mathrm{mg} \mathrm{cm}^{-2}$, for obtaining a Mössbauer spectrum. This problem becomes worth when sampling coastal river plumes where the riverine Fe input becomes more and more diluted. At a certain point, this cannot 



Fig. 4 Mössbauer spectra of mineral products of banded iron formation diagenesis simulation experiments before (a) and after (b) application of sequential iron extraction steps after Poulton and Canfield [22]. The spectrum in (a) was obtained at a sample temperature of $140 \mathrm{~K}$ and shows two hematite populations (grey and dark grey sextets). The spectrum in (b) was obtained at room temperature and shows remaining carbonate, which should have been dissolved in the previous extraction step. Open circles represent the measured Mössbauer spectrum, the black line connecting the circles is the sum of the fitted subspectra. Subspectral areas are proportional to the amount of $\mathrm{Fe}$ in the respective mineral phase: Dark grey - hematite (b) or poorly-crystalline hematite (a); grey - well-crystalline hematite; light grey - siderite; hatched - magnetite. Magnetite is represented by two subspectra. Subspectra where the hatching starts low on the left and ends high on the right represent $\mathrm{Fe}(\mathrm{III})$ in tetrahedral lattice sites. Subspectra with opposite hatching orientation represent $\mathrm{Fe}(\mathrm{II})$ and $\mathrm{Fe}(\mathrm{III})$ in octahedral lattice sites

be compensated anymore by simply filtering more water. Obtaining a single Mössbauer spectrum from such samples can thus take several days to weeks when using a conventional Mössbauer spectrometer. The SMS offers two advantages: 




Fig. 5 Map showing the northern coastline of Scotland. Arrows indicate sampling locations. The filters from the peat-draining Halladale and Thurso rivers are covered in dark material representing their high organic matter load. The coastal seawater filtrate is pale in comparison. Mössbauer spectra for the Halladale and Thurso rivers are identical and represent ferric iron (green doublet), most likely superparamagnetic iron (oxyhydr)oxides. The coastal seawater sample (Brough) contained $40 \%$ of ferrous iron (purple and light blue doublets), most of it in the calcium-iron carbonate ankerite (purple doublet)

(1) The X-ray focussing and monochromatization filters all non-resonant photons out of the beam, which significantly enhances the signal-to-noise ratio in a spectrum and therefore decreases measurement times;

(2) The monochromatized beam is focused to a diameter of a few micrometers, which enables the analysis of even microscopic sample volumes.

Using the SMS at ESRF, we obtained Mössbauer spectra in a matter of hours (Fig. 5). The room temperature spectra from the Thurso and Halladale rivers looked identical and contained exclusively ferric iron, most likely superparamagnetic iron (oxyhydr)oxides. The coastal seawater sample (Brough) contained $40 \%$ of ferrous iron, most of it in the calciumiron carbonate ankerite, $\mathrm{CaFe}\left(\mathrm{CO}_{3}\right)_{2}$. Additional low-temperature measurements would help to constrain the mineralogy further.

Other studies have used the synchrotron-based X-ray absorption techniques extended X-ray absorption fine structure (EXAFS) and X-ray absorption near-edge spectroscopy (XANES) to study particulate Fe in seawater $[36,38]$. Our preliminary results show that it is feasible to use the SMS to obtain quantitative Fe oxidation states as with EXAFS and XANES while providing additional information on the mineralogy of these particles. Furthermore, Mössbauer spectroscopy, EXAFS and XANES can be used effectively in a complementary way [17]. 


\section{Implications: Isotope studies in samples returned from Mars}

Mars is the prime focus for astrobiology in our solar system because there is abundant evidence for liquid water and habitable environments on its surface more than 3 billion years ago [11, 39-42], a time when life arose on Earth; it is the most Earth-like planet in the solar system in terms of its surface environment; and the Red Planet is the most accessible planet to robotic and future human exploration. In situ measurements on the Martian surface with the miniaturised Mössbauer spectrometers on board NASA's twin Mars Exploration Rovers [14] have provided evidence for the past presence of liquid water - e.g. the Fe oxyhydroxide goethite, $\alpha$-FeOOH [43] or the Fe sulfate hydroxide jarosite, $\left(\mathrm{K}, \mathrm{Na}, \mathrm{H}_{3} \mathrm{O}\right) \mathrm{Fe}_{3}\left(\mathrm{SO}_{4}\right)_{2}(\mathrm{OH})_{6}$ [44]; ferrous minerals and Fe redox gradients would provide an energy source [3, 39]; and Fe carbonates would be a carbon source [11]. Despite its success there are currently no plans to fly another Mössbauer spectrometer on a Mars mission.

The next big leap in Mars exploration, however, will be the return of samples collected on the Martian surface to Earth. Of particular interest are isotopic investigations of such samples for dating purposes on the one hand, but also to look for signatures of past environmental conditions and potential biosignatures. Mass-independent fractionation of $\mathrm{S}$ isotopes, for example, can be used to track atmospheric processes [45] while $\delta^{34} \mathrm{~S}$ can be used to look for signatures of potential biological activity. There are strong interaction between the Fe and S cycles, both on Earth and on Mars, and combined isotope analyses can yield unique insights [46]. One specific role for Mössbauer spectroscopy in the investigation of returned samples may be in optimizing mineral separation for isotopic investigations (see Section 3 above).

\section{Outlook: Mössbauer spectroscopy on Jupiter's moon Europa?}

Another exciting target for astrobiology is Jupiter's icy moon Europa (Fig. 6), which boasts a global ocean of liquid water underneath its ice-covered exterior. Underwater volcanism may prevent this ocean from freezing. Life independent of sunlight is thriving at hydrothermal vents in Earth's oceans, and these systems have also been suggested as the places where life might have originated [8] (see Section 1). There is no reason for free oxygen to be dissolved in Europa's subsurface ocean and it should therefore be relatively Fe-rich. Coloured streaks on Europa's surface represent mineral deposits, and their predominantly red colour (Fig. 6) could betray the presence of Fe minerals. Both ESA and NASA are currently planning missions to the Jupiter system, which would study Europa in multiple flybys. A subsequent lander could target the mineral deposits, which would reveal much about the chemistry of the underlying ocean and its potential for harbouring life.

Could a Mössbauer spectrometer be part of the payload of such a mission? This may be at the limit of possible targets in the solar system [47]. The functional lifetime of a Mössbauer spectrometer depends on the halflife of the ${ }^{57}$ Co radiation source (270 days). The Galileo spacecraft took 6 years to reach the Jupiter system. The Mössbauer spectrometers on the Mars Exploration Rovers worked for approximately the same time span. Spectral acquisition had become very slow though, on the order of days to weeks for a single spectrum, towards the end. Nevertheless, new developments might make a Europa mission feasible. Replacing the PIN-diode detectors in MIMOS II with Silicon drift detectors in the advanced MIMOS IIa $[4,48]$ significantly enhances the energy resolution and hence the signal-to-noise ratio 


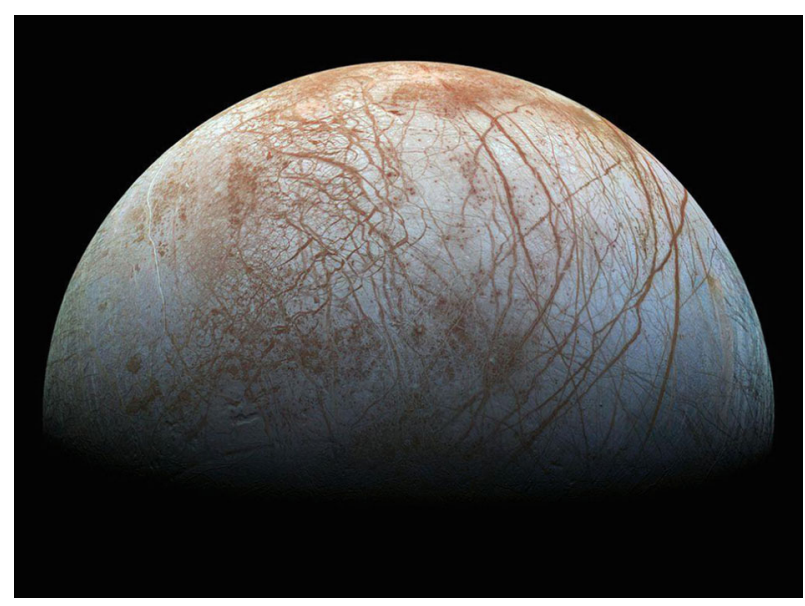

Fig. 6 Jupiter's icy moon Europa is crisscrossed by long, linear cracks interrupted by regions of disrupted terrain where the surface ice crust has been broken up and re-frozen into new patterns. Colour variations across the surface are associated with differences in geologic feature type and location. For example, areas that appear blue or white contain relatively pure water ice, while reddish and brownish areas include non-ice components in higher concentrations. This true-colour view was made from images taken by NASA's Galileo spacecraft in the late 1990s. Credit: NASA / Jet Propulsion Lab-Caltech / SETI Institute; http://photojournal. jpl.nasa.gov/catalog/PIA19048

in spectra. This can reduce the time needed for spectral acquisition by an order of magnitude. As an added bonus, MIMOS IIa also doubles as an X-ray fluorescence spectrometer enabling the determination of the elemental chemistry of samples.

Acknowledgments C. S. acknowledges a joint postdoctoral appointment at the Universities of Bayreuth and Tübingen funded through the DFG research unit FOR 580 - electron transfer processes in anoxic aquifers (e-TraP); an Impact Fellowship awarded by the University of Stirling; and a SAGES PECRE grant. Parts of this work were supported by research grants (KA 1736/4-1 and 12-1) from the German Research Foundation (DFG) to A. K. We thank Michael Schäfer and Göstar Klingelhöfer for measurements with MIMOS II at the University of Mainz.

Open Access This article is distributed under the terms of the Creative Commons Attribution 4.0 International License (http://creativecommons.org/licenses/by/4.0/), which permits unrestricted use, distribution, and reproduction in any medium, provided you give appropriate credit to the original author(s) and the source, provide a link to the Creative Commons license, and indicate if changes were made.

\section{References}

1. Brack, A., Horneck, G., Wynn-Williams, D.: Exo/Astrobiology in Europe. Origins Life Evol. B. 31, 459-480 (2001). doi:10.1023/A:1011832902468

2. Schröder, C., Klingelhöfer, G., Bailey, B.E., Staudigel, H.: Mössbauer spectroscopy as a tool in astrobiology. Hyperfine Interact. 166, 567-571 (2005). doi:10.1007/s10751-006-9346-X

3. Schröder, C., Bailey, B., Klingelhöfer, G., Staudigel, H.: Fe Mössbauer spectroscopy as a tool in astrobiology. Planet. Space Sci. 54, 1622-1634 (2006). doi:10.1016/j.pss.2006.05.042 
4. Schröder, C., Klingelhöfer, G., Morris, R.V., Bernhardt, B., Blumers, M., Fleischer, I., Rodionov, D.S., Gironés López, J., de Souza Jr., P.A.: Field-portable Mössbauer spectroscopy on Earth, the Moon, Mars, and beyond. Geochem.-Explor. Env. A. 11, 129-143 (2011). doi:10.1144/1467-7873/09-IAGS-018

5. Schröder, C.: Mössbauer spectroscopy in astrobiology. Spectrosc. Eur. 27(2), 10-13 (2015)

6. Rickard, D., Luther III, G.W.: Chemistry of iron sulfides. Chem. Rev. 107, 514-562 (2007). doi:10.1021/cr0503658

7. Hazen, R.M.: Paleomineralogy of the Hadean eon: A preliminary species list. Am. J. Sci. 313, 807-843 (2013). doi:10.2475/09.2013.01

8. Wächtershäuser, G.: Groundworks for an evolutionary biochemistry: The iron-sulphur world. Prog. Biophys. Mol. Bio. 58, 85-201 (1992). doi:10.1016/0079-6107(92)90022-X

9. Köhler, I., Konhauser, K.O., Kappler, A.: Role of microorganisms in banded iron formations. In: Barton, L., Mandl, M., Loy, A. (eds.) Geomicrobiology: Molecular and Environmental Perspective, pp. 309-324. Springer, New York (2010)

10. Posth, N.R., Konhauser, K.O., Kappler, A.: Banded iron formations. In: Reitner, J., Thiel, V. (eds.) Geobiology Encyclopedia, pp. 92-103. Springer, New York (2011). Springer Encyclopedia of Earth Science Series (EESS)

11. Morris, R.V., Ruff, S.W., Gellert, R., Ming, D.W., Arvidson, R.E., Clark, B.C., Golden, D.C., Siebach, K., Klingelhöfer, G., Schröder, C., Fleischer, I., Yen, A., Squyres, S.W.: Identification of carbonate-rich outcrops on Mars by the spirit rover. Science 329, 421-424 (2010). doi:10.1126/science.1189667

12. Posth, N.R., Köhler, I., Swanner, E., Schröder, C., Wellmann, E., Binder, B., Konhauser, K.O., Neumann, U., Berthold, C., Nowak, M., Kappler, A.: Simulating Precambrian banded iron formation diagenesis. Chem. Geol. 362, 66-73 (2013). doi:10.1016/j.chemgeo.2013.05.031

13. Köhler, I., Konhauser, K.O., Papineau, D., Bekker, A., Kappler, A.: Biological carbon precursor to diagenetic siderite spherulites in banded iron formations. Nat. Commun. 4, 1741 (2013). doi: $10.1038 /$ ncomms 2770

14. Klingelhöfer, G., Morris, R.V., Bernhardt, B., Rodionov, D., de Souza Jr., P.A., Squyres, S.W., Foh, J., Kankeleit, E., Bonnes, U., Gellert, R., Schröder, C., Linkin, S., Evlanov, E., Zubkov, B., Prilutski, O.: Athena MIMOS II Mössbauer spectrometer investigation. J. Geophys. Res. 108(E12), 8067 (2003). doi:10.1029/2003JE002138

15. Rosing, M.T., Bird, D.K., Sleep, N.H., Bjerrum, C.J.: No climate paradox under the faint early sun. Nature 464, 744-749 (2010). doi:10.1038/nature08955

16. Lalonde, K., Mucci, A., Oullet, A., Gélinas, Y.: Preservation of organic matter in sediments promoted by iron. Nature 483, 198-200 (2012). doi:10.1038/nature10855

17. Shimizu, M., Zhou, J., Schröder, C., Obst, M., Kappler, A., Borch, T.: Dissimilatory reduction and transformation of ferrihydrite-humic acid co-precipitates. Environ. Sci. Technol. 47, 13375-13384 (2013). doi:10.1021/es402812j

18. Tessier, A., Campbell, P.G.C., Bisson, M.: Sequential extraction procedure for the speciation of particulate trace metals. Anal. Chem. 51, 844-851 (1979). doi:10.1021/ac50043a017

19. Reed, D.C., Slomp, C.P., Gustafsson, B.G.: Sedimentary phosphorus dynamics and the evolution of bottom-water hypoxia: a coupled benthic-pelagic model of a coastal ecosystem. Limnol. Oceanogr. 56, 1075-1092 (2011). doi:10.4319/lo.2011.56.3.1075

20. Wallmann, K., Hennies, K., Konig, I., Petersen, W., Knauth, H.D.: New procedure for determining reactive fe(III) and fe(II) minerals in sediments. Limnol. Oceanogr. 38, 1803-1812 (1993). doi:10.4319/1o.1993.38.8.1803

21. Heron, G., Crouzet, C., Bourg, A.C.M., Christensen, T.H.: Speciation of fe(II) and fe(III) in contaminated aquifer sediments using chemical-extraction techniques. Environ. Sci. Technol. 28, 1698-1705 (1994). doi:10.1021/es00058a023

22. Poulton, S.W., Canfield, D.E.: Development of a sequential extraction procedure for iron: implications for iron partitioning in continentally derived particles. Chem. Geol. 214, 209-221 (2005). doi:10.1016/j.chemgeo.2004.09.003

23. Canfield, D.E., Poulton, S.W., Knoll, A.H., Navronne, G.M., Ross, G., Goldberg, T., Strauss, H.: Ferruginous conditions dominated later Neoproterozoic deep water chemistry. Science 321, 949-952 (2008). doi:10.1126/science. 1154499

24. Poulton, S.W., Fralick, P.W., Canfield, D.E.: Spatial variability in oceanic redox structure 1.8 billion years ago. Nat. Geosci. 3, 486-490 (2010). doi:10.1038/ngeo889

25. Scott, C.T., Bekker, A., Reinhard, C.T., Schnetger, B., Krapez, B., Rumble, D., Lyons, T.W.: Late Archean euxinic conditions before the rise of atmospheric oxygen. Geology 39, 119-122 (2011). doi:10.1130/G31571.1

26. Reinhard, C.T., Raiswell, R., Scott, C., Anbar, A.D., Lyons, T.W.: A late Archean sulfidic sea stimulated by early oxidative weathering of the continents. Science 326, 713-716 (2009). doi:10.1126/science. 1176711 
27. Raiswell, R., Reinhard, C.T., Derkowski, A., Owens, J., Bottrell, S.H., Anbar, A.D., Lyons, T.W.: Formation of syngenetic and early diagenetic iron minerals in the late Archean Mt. McRae Shale, Hamersley Basin, Australia: New insights on the patterns, controls and paleoenvironmental implications of authigenic mineral formation. Geochim. Cosmochim. Ac. 75, 1072-1087 (2011). doi:10.1016/j.gca.2010.11.013

28. Schmid, G.: Identification and Quantification of Iron Minerals after Pressure and Temperature Treatment of Ferrihydrite-Biomass Mixtures. Diplomarbeit, Fachbereich Geowissenschaften, Zentrum für Angewandte Geowissenschaften, Eberhard Karls Universität Tübingen (2011)

29. Martin, J.H.: Glacial-interglacial $\mathrm{CO}_{2}$ change: The iron hypothesis. Paleoceanography 5, 1-13 (1990). doi:10.1029/PA005i001p00001

30. Moore, C.M., Mill, M.M., Arrigo, K.R., Berman-Frank, I., Bopp, L., Boyd, P.W., Galbraith, E.D., Geider, R.J., Guieu, C., Jaccard, S.L., Jickells, T.D., La Roche, J., Lenton, T.M., Mahowald, N.M., Marañón, E., Marinov, I., Moore, J.K., Nakatsuka, T., Oschlies, A., Saito, M.A., Thingstad, T.F., Tsuda, A., Ulloa, O.: Processes and patterns of oceanic nutrient limitation. Nat. Geosci. 6, 701-710 (2013). doi:10.1038/NGEO1765

31. Hendy, I.L.: Ironing out carbon export to the deep ocean. P. Natl. Acad. Sci. USA 112, 306-307 (2015). doi:10.1073/pnas.1421561112

32. Raiswell, R., Canfield, D.E.: The iron biogeochemical cycle past and present. Geochem. Perspect. 1, 1-220 (2012). doi:10.7185/geochempersp.1.1

33. Batchelli, S., Muller, F.L.L., Chang, K.-C., Lee, C.L.: Evidence for strong but dynamic iron-humic colloidal associations in humic-rich coastal waters. Environ. Sci. Technol. 44, 8485-8490 (2010). doi:10.1021/es101081c

34. Krachler, R., Krachler, R.F., von der Kammer, F., Süphandag, A., Jirsa, F., Ayromlou, S., Hofmann, T., Keppler, B.K.: Relevance of peat-draining rivers for the riverine input of dissolved iron into the ocean. Sci. Total Environ. 408, 2402-2408 (2010). doi:10.1016/j.scitotenv.2010.02.018

35. Pokrovsky, O.S., Shirokova, L.S., Viers, J., Gordeev, V.V., Shevchenko, V.P., Chupakov, A.V., Vorobieva, T.Y., Candaudap, F., Causserand, C., Lanzanova, A., Zouiten, C.: Fate of colloids during estuarine mixing in the Arctic. Ocean Sci. 10, 107-125 (2014). doi:10.5194/os-10-107-2014

36. Marcus, M.A., Lam, P.J.: Visualising Fe speciation diversity in ocean particulate samples by micro X-ray absorption near-edge spectroscopy. Environ. Chem 11, 10-17 (2014). doi:10.1071/EN13075

37. Potapkin, V., Chumakov, A.I., Smirnov, G.V., Celse, J.-P., Rüffer, R., McCammon, C., Dubrovinsky, L.: The ${ }^{5} 7 \mathrm{Fe}$ synchrotron Mössbauer source at the ESRF. J. Synchrotron Rad. 19, 559-569 (2012). doi:10.1107/S0909049512015579

38. von der Heyden, B.P., Roychoudhury, A.N., Mtshali, T.N., Tyliszczak, T., Myneni, S.C.B.: Chemically and geographically distinct Solid-Phase iron pools in the southern ocean. Science 338, 1199-1201 (2012). doi:10.1126/science. 1227504

39. Knoll, A.H., Carr, M., Clark, B., DesMarais, D.J., Farmer, J.D., Fischer, W.W., Grotzinger, J.P., McLennan, S.M., Malin, M., Schröder, C., Squyres, S., Tosca, N.J., Wdowiak, T.: An astrobiological perspective on Meridiani Planum. Earth Planet Sc. Lett. 240, 179-189 (2005). doi:10.1016/j.eps1.2005.09.045

40. Squyres, S.W., Arvidson, R.E., Bell III, J.F., Calef III, F., Clark, B.C., Cohen, B.A., Crumpler, L.A., de Souza Jr., P.A., Farrand, W.H., Gellert, R., Grant, J., Herkenhoff, K.E., Hurowitz, J.A., Johnson, J.R., Jolliff, B.L., Knoll, A.H., Li, R., McLennan, S.M., Ming, D.W., Mittlefehldt, D.W., Parker, T.J., Paulsen, G., Rice, M.S., Ruff, S.W., Schröder, C., Yen, A.S., Zacny, K.: Ancient impact and aqueous processes at endeavour crater, Mars. Science 336, 570-576 (2012). doi:10.1126/science.1220476

41. Arvidson, R.E., Squyres, S.W., Bell III, J.F., Catalano, J.G., Clark, B.C., Crumpler, L.S., de Souza Jr., P.A., Fairén, A.G., Farrand, W.H., Fox, V.K., Gellert, R., Ghosh, A., Golombek, M.P., Grotzinger, J.P., Guinness, E.A., Herkenhoff, K.E., Jolliff, B.L., Knoll, A.H., Li, R., McLennan, S.M., Ming, D.W., Mittlefehldt, D.W., Moore, J.M., Morris, R.V., Murchie, S.L., Parker, T.J., Paulsen, G., Rice, J.W., Ruff, S.W., Smith, M.D., Wolff, M.J.: Ancient aqueous environments at endeavour crater, Mars. Science 343, 1248097 (2014). doi:10.1126/science.1248097

42. Grotzinger, J.P., Sumner, D. Y., Kah, L.C., Stack, K., Gupta, S., Edgar, L., Rubin, D., Lewis, K., Schieber, J., Mangold, N., Milliken, R., Conrad, P.G., DesMarais, D., Farmer, J., Siebach, K., Calef III, F., Hurowitz, J., McLennan, S.M., Ming, D., Vaniman, D., Crisp, J., Vasavada, A., Edgett, K.S., Malin, M., Blake, D., Gellert, R., Mahaffy, P., Wiens, R.C., Maurice, S., Grant, J.A., Wilson, S., Anderson, R.C., Beegle, L., Arvidson, R., Hallet, B., Sletten, R.S., Rice, M., Bell III, J., Griffes, J., Ehlmann, B., Anderson, R.B., Bristow, T.F., Dietrich, W.E., Dromart, G., Eigenbrode, J., Fraeman, A., Hardgrove, C., Herkenhoff, K., Jandura, L., Kocurek, G., Lee, S., Leshin, L.A., Leveille, R., Limonadi, D., Maki, J., McCloskez, S., Meyer, M., Minitti, M., Newsom, H., Oehler, D., Okon, A., Palucis, M., Parker, T., Rowland, S., Schmidt, M., Squyres, S., Steele, A., Stolper, E., Summons, R., Treiman, A., Williams, 
R., Yingst, A.: MSL science team: a habitable Fluvio-Lacustrine environment at Yellowknife Bay, Gale Crater, Mars. Science 343, 1242777 (2014). doi:10.1126/science.1242777

43. Klingelhöfer, G., DeGrave, E., Morris, R.V., Van Alboom, A., de Resende, V.G., de Souza Jr., P.A., Rodionov, D., Schröder, C., Ming, D.W., Yen, A.: Mössbauer spectroscopy on Mars: goethite in the Columbia Hills at Gusev crater. Hyperfine Interact. 166, 549-554 (2005). doi:10.1007/s10751-006-9329-y

44. Klingelhöfer, G., Morris, R.V., Bernhardt, B., Schröder, C., Rodionov, D.S., de Souza Jr., P.A., Yen, A., Gellert, R., Evlanov, E.N., Zubkov, B., Foh, J., Bonnes, U., Kankeleit, E., Gütlich, P., Ming, D.W., Renz, F., Wdowiak, T., Squyres, S.W., Arvidson, R.E.: Jarosite and hematite at meridiani planum from opportunity's Mössbauer spectrometer. Science 306, 1740-1745 (2004). doi:10.1126/science.1104653

45. Thiemens, M.H.: Introduction to chemistry and applications in nature of mass independent isotope effects special feature. P. Natl. Acad. Sci. USA 110, 17631-17637 (2013). doi:10.1073/pnas.1312926110

46. Archer, C., Vance, D.: Coupled Fe and S isotope evidence for Archean microbial fe(III) and sulfate reduction. Geology 34, 153-156 (2006). doi:10.1130/G22067.1

47. Klingelhöfer, G., Held, P., Teucher, R., Schlichting, F., Foh, J., Kankeleit, E.: Mössbauer spectroscopy in space. Hyperfine Interact. 95, 305-339 (1995). doi:10.1007/BF02146322

48. Blumers, M., Bernhardt, B., Lechner, P., Klingelhöfer, G., d'Uston, C., Soltau, H., Strüder, L., Eckhardt, R., Brückner, J., Henkel, H., Lopez, J.G., Maul, J.: The miniaturised Mössbauer spectrometer MIMOSIIA: Increased sensitivity and new capability for elemental analysis. Nucl. Instrum. Meth. A 624, 277-281 (2010). doi:10.1016/j.nima.2010.04.007 